\title{
"Incidentalomas" na investigação de um paciente com cefaleia
}

"Incidentaloma" in the investigation of a patient with headache

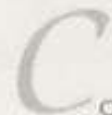

om o grande aumento da ufilização da neuroimagem na investigaçẩo intracraniana em pacientes com queixas neurológicas vem surgindo um novo olhar para as lesōes intracranianas que sāo diagnosticadas incidentalmente. ") Por isso. essas lesôes são chamadas de incidentalomas. $\bigcirc$ sufixo "oma", quando acrescentado, oferece uma interprefação para aquela palavra como tendo uma forma tumoral (que ocupa espaço), não necessariamente uma neoplasia. Outras alteraçōes não tumorais podem fambém ser enquadradas no grupo dos incidentalomas, pois foram diagnosticadas por coincidência, ou seja, ao acaso. Em outras palavras, incidentalomas sāo tumoraçōes diagnosticadas durante a realização de um exame radiológico que aparentemente não teriam relação com a sintomatologia apresentada pelo paciente.

Não é raro durante uma investigaçāo de um paciente com cefaleia, aqui incluindo cefaleia primária, serem encontrados, por coincidência, imagens compativeis com o diagnóstico de meningeoma, adenoma hipofisário, aneurismas cerebrais, cavernoma, malformaçâo vascular, lipoma, cisto aracnoideo, cistos da pineal, cisticercose etc (1,2)

A grande questâo é saber se aquela lesão encontrada teria alguma relaçâo com a cefaleia do seu paciente. Em outras palavras, a lesāo é a causa direta da dor ou pode de alguma forma influenciar a frequência e intensidade da cefaleia primária daquele indivíduo $(e, g$. cisto da pineal). (T)

Recentemente vimos uma mulher com 52 anos de idade e cefaleía em salvas fronto-orbitária direita desde seus 25 anos de idade. Durante a investigação com RM diagnosticou-se um pequeno aneurisma sacular medindo $3,5 \mathrm{~mm}$ em seu maior diâmetro, localizado na parede póstero-medial do segmento
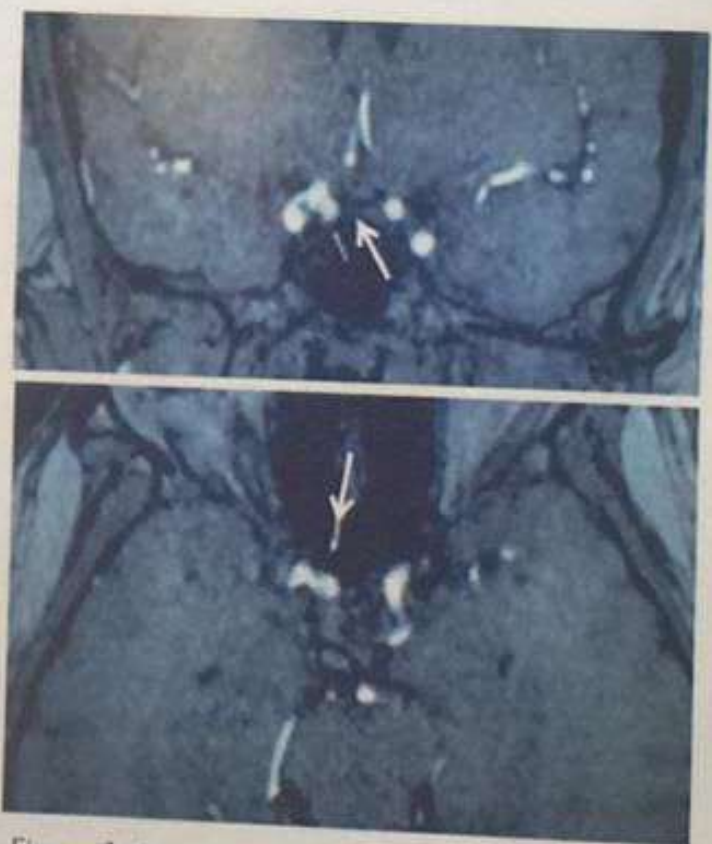

Figura 1. Aneurisma da artéria carótida interna na origem da artéria hipofisária superior direita em uma mulher com cefaleia em salvas fronto-temporal
direita. 
supraclinoideo inicial da artéria carótida direita, relacionado com a origem da artéria hipofisária superior (Figura 1). Haveria uma relaçāo causal entre o aneurisma e a cefaleia em salvas nessa paciente? Previamente publicamos dois casos de pacientes que abríram o quadro álgico com um padrāo de dor idêntico ao da cefaleia em salvas, incluindo manifestaçổes autonômicas, e como fator precipitante foi encontrado um aneurisma da artéria carótida interna do mesmo lado da dor (i) $^{(4)}$ Um consenso já foi estabelecido que todos os pacientes com cefaleia em salvas devem ser investigados por RM, incluindo ângio- RM.

Em relação aos adenomas hipofisários, aqui vale uma ressalva: vários dos "adenomas" sāo falso-incidentalomas porque são muitas vezes artefatos da imagem, como por exemplo o efeifo do volume parcial. Isso tem gerado muito problema em nossos consultórios, pois o laudo do radiologista, poderia assim dizer irresponsável, estabelecendo a presença de uma tumor intra-selar, desencadeia um estado de pânico em nossos pacientes. E durante anos esses indivíduos vão imaginar albergar um fumor intracraniano que pode crescer. Dificultando ainda mais o tratamento da cefaleía primária, que, em muitas ocasiōes, fá é de dificil tratamento.

Poderia aqui classificar os incidentalomas em dois grupos: (1) solitários (lesâo única assintomática) e (2) associados com uma lesāo intracraniana sintomática. Neste último caso uma outra lesão seria identificada na investigação de uma alteraçāo (aneurisma roło, neoplasia) responsável pela sintomatologia apresentada pelo paciente. Por exemplo: uma de nossas pacientes com 75 anos e seis meses de história de cefaleia associada com visāo dupla (paralisia VI nervo esquerdo), após investigaçáo por RM recebeu o diagnóstico de um meningeoma $(3,3 \times 2,8$ $\times 2,6 \mathrm{~cm})$ no ângulo ponto-cerebelar esquerdo que infiltrava o seio cavernoso e o cavum de Meckel (tumoraçāo sintomática). Um outro pequeno tumor $(1,1 \times 1,0 \times$ $0,8 \mathrm{~cm}$ ) foi encontrado na face inferior do lobo frontal esquerdo, consistente com meningeoma (Figura 2).

Da mesma forma, é muito comum em mulheres quando se diagnostica um aneurisma infracraniano rofo encontrar-se adicionalmente um ou mais aneurismas
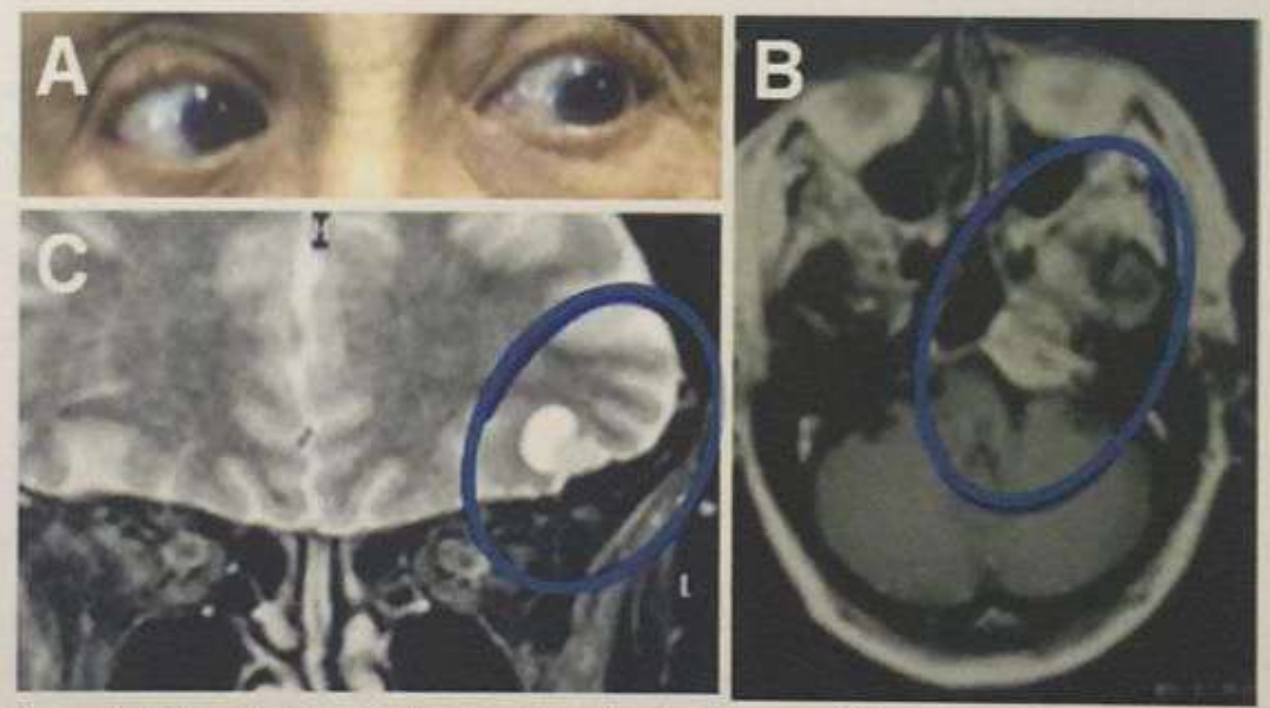

Figura 2. A. Paralisia do múscula reta externo do olho esquerdo. B. Imagem compativel com um meningeoma com envolvimento do sexto nerva croniano esquerdo. C. Provável meningeoma (incindentalomo) na base anterior do crânio (fossa onterior) esquerda. 
que não romperam. Veja o caso descrito nesta ediçāo da Headache Medicine por Valença e colaboradores, de uma mulher com um aneurisma da artéria carófida interna sintomático (cefaleia e paralisia do terceiro nervo craniano) e outro aneurisma da artéria vertebral-PICA. Sexo feminino, tabagismo e hipertensão são fatores associados com aneurismas intracranianos múlfiplos. ${ }^{57}$

Curiosamente, nesta edição da Headache Medicine, Leão e colegas relatam um caso de uma mulher com migrânea que a investigação por RM detectou agenesia da artéria carótida interna esquerda, com um encéfalo aparentemente normal. Nesse caso, em particular, não seria um "incidentaloma", mas sim um achado incidental de agenesia.

\section{References}

1. Salman R A-S, Whiteley WN, Warlow C. Screening using whole-body magnetic resonance imaging scanning: who wants an incidentaloma? J Med Screen 2007 14:2-4

2. Valenca MM, Valenca LP, Menezes TL. Computed tomography scan of the head in patients with migraine or tension-type headache. Arq Neuropsiquiatr. 2002 Sep;60(3-A):542-7.

3. Peres MF, Zukerman E, Porto PP, Brondt RA. Headaches and pineal cyst: $a$ (more than) coincidental relationship? Headache. 2004 Oct; 44(9):929-30.

4. Valença MM, Andrade-Valença LP, Martins C, de Fátima Vasco Aragāo M, Batista LL, Peres MF, da Silva WF. Cluster heodache and intracranial aneurysm. J Headache Pain. 2007 Oct;8(5):277. 82. Epub 2007 Oct 23.

5. Juvela S. Risk Factors for Multiple Intracranial Aneurysms. 2000;31:392-97.

Marcelo M. Valença

Universidade Federal de Pernambuco 